\title{
AlgunAS REFLEXIONES EN TORNO AL TRABAJO FLORÍSTICO EN MÉXICO
}

\author{
Ponencia presentada por Jerzy Rzedowski en el marco del XIX \\ Congreso Mexicano de Botánica, Celebrado en octubre de 2013 \\ en Tuxtla Gutiérrez, Chiapas
}

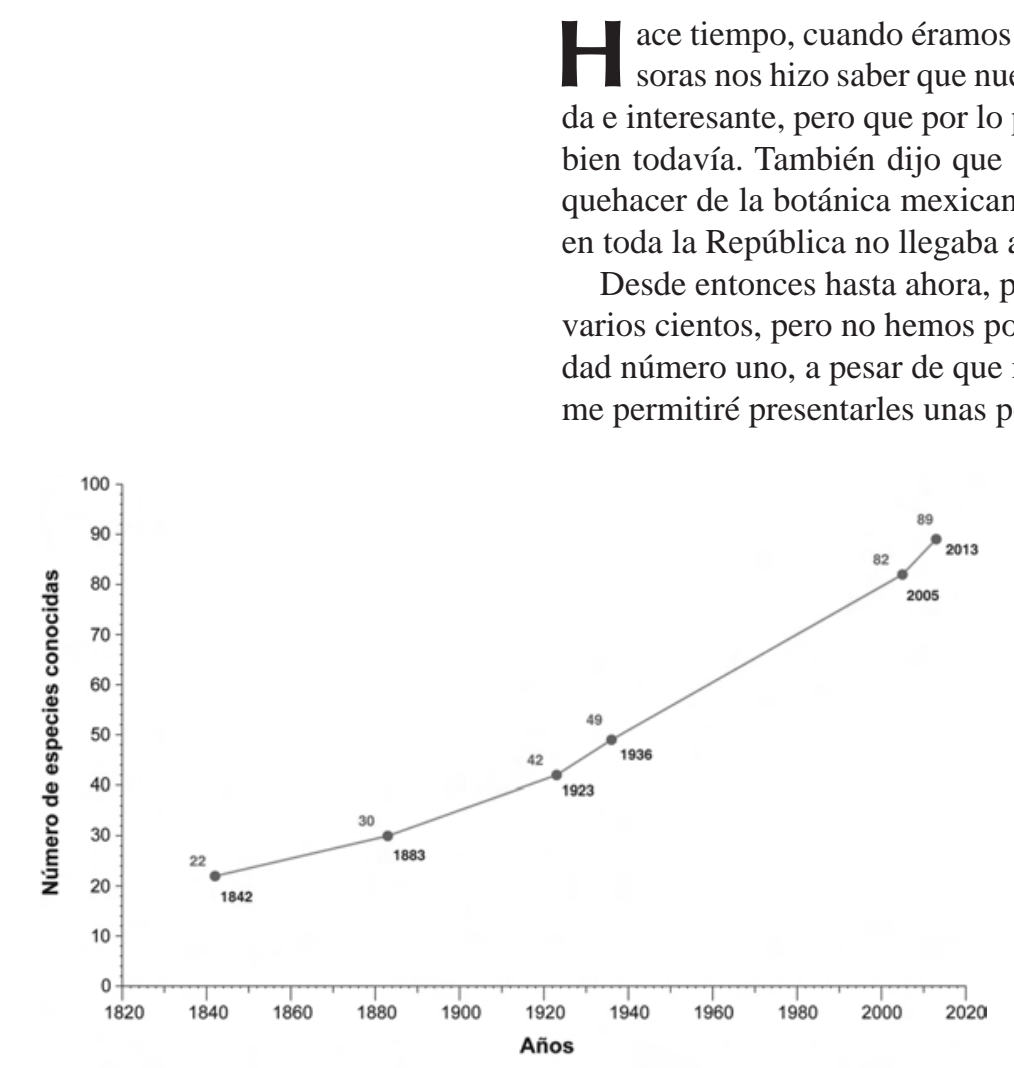

Figura 1. Número de especies de Bursera conocidas a través del tiempo. conocimiento cabal de la flora vascular alrededor de $20 \%$ de especies adicionales a las ya registradas. Más tarde, y con empleo de metodología matemática, el Dr. Villaseñor calculó que la deficiencia es de alrededor de $30 \%$ y probablemente tal expectativa se encuentra más cerca de la realidad.

De regreso con Bursera, nos consta que casi todos los árboles de este género habitan en bosques tropicales caducifolios bien conservados y que sus poblaciones rápidamente quedan diezmadas con el disturbio. No menos sabida es la circunstancia de que hoy en día, de todos los tipos de vegetación de México, el bosque tropical caducifolio es el que sufre la mayor tasa de desforestación. De la región del Bajío ya desapareció prácticamente por completo. En el estado de Michoacán no queda en buenas condiciones mucho más del $10 \%$ de los $27,000 \mathrm{~km}^{2}$ que originalmente ocupaba. De tales antece- 
dentes surge esta primera interrogante: de la probable veintena de especies de Bursera que todavía nos falta conocer, ¿cuántas lograremos ver antes de que se extingan por completo?

Pasando a un contexto diferente, aunque nada ajeno, me ha llegado la noticia, que en una reunión celebrada hace relativamente poco, se han vertido opiniones acerca del trabajo taxonómico mexicano. En general no fueron buenas, pero al menos una de ellas es sumamente certera, real y relevante: la relativa a su lentitud, pues no hay mucha duda, de que al menos, el progreso del conocimiento sistemático integral del universo vegetal mexicano es desesperada y despiadadamente lento.

Así, por ejemplo, el proyecto de la Flora del Bajío y de regiones adyacentes tuvo su inicio en 1985. Se dedicaron casi siete años a la labor de intensa exploración del área y en 1992 comenzó la preparación de la propia flora, con la estimación de poder terminarla en unos 10 años más. Resulta, sin embargo, que hoy, 21 años después, no se ha llegado a cubrir todavía 45\% de las 5,500 especies de plantas vasculares que se calculan para la región. Las otras floras regionales activas en este momento tampoco se encuentran en mucho mejores condiciones de avance.

Cabría en seguida pensar que nuestra ineficiencia puede deberse a la falta de una apropiada cantidad de botánicos capacitados para el trabajo taxonómico, pero este definitivamente no es el caso, pues sí tenemos ya una buena masa crítica de recursos humanos experimentados para afrontar la urgente necesidad del país de contar con un satisfactorio y pormenorizado inventario de los recursos vegetales, y aún para más.

Las razones entonces, de la lentitud, hay que buscarlas por otro lado y aquí va un ensayo de su explicación.

- En primer lugar, es importante recordar que el trabajo taxonómico de calidad no es sencillo ni fácil, pues suele exigir y consumir una cuantiosa inversión de esfuerzo intelectual, así como de perseverancia, de tiempo y de paciencia, que requiere su minucioso rigor.

- En segunda instancia, no hay mucha duda de que la taxonomía tradicional en la actualidad no se encuentra de moda y le cuesta trabajo competir con desventaja ante el alud de la "sistemática molecular", enfocada mayormente a la búsqueda de las relaciones filogenéticas entre los organismos. La verdad es, no obstante, que la sistemática molecular es sin duda muy trascendente, pues complementa y enriquece profundamente a la tradicional, pero no tiene la capacidad de reemplazarla.

- Y sin ser precisamente la última, la razón más drástica y significativa de la actual lentitud reside en el hecho de que el trabajo taxonómico, y más aún el florístico, no es apropiadamente apreciado en los sistemas de evaluación del desempeño de la labor de la investigación científica vigentes en México, mismos que a su vez poseen un papel fundamental en la contratación, remuneración y promoción del personal dedicado a tal actividad. De esta suerte, el grueso de los botánicos entrenados en la sistemática se ve ahora inclinado — por no decir orillado_-, a buscar actividades alternas que les proporcionen más reconocimiento y beneficio, y a menudo con esfuerzo considerablemente menor.

Y aquí cabe entonces la segunda pregunta: de las floras regionales, cuya preparación se ha iniciado con tanto entusiasmo, pero que tienen hoy que batallar por su supervivencia, ¿cuántas alcanzarán su integral término?

Muchas gracias por su atención. 